\title{
Effects of Selective Excitotoxic Lesions of the Nucleus Accumbens Core, Anterior Cingulate Cortex, and Central Nucleus of the Amygdala on Autoshaping Performance in Rats
}

\author{
Rudolf N. Cardinal, John A. Parkinson, Guillaume Lachenal, Katherine M. Halkerston, \\ Nung Rudarakanchana, Jeremy Hall, Caroline H. Morrison, Simon R. Howes, \\ Trevor W. Robbins, and Barry J. Everitt \\ University of Cambridge
}

\begin{abstract}
The nucleus accumbens core (AcbC), anterior cingulate cortex (ACC), and central nucleus of the amygdala $(\mathrm{CeA})$ are required for normal acquisition of tasks based on stimulus-reward associations. However, it is not known whether they are involved purely in the learning process or are required for behavioral expression of a learned response. Rats were trained preoperatively on a Pavlovian autoshaping task in which pairing a visual conditioned stimulus (CS+) with food causes subjects to approach the $\mathrm{CS}+$ while not approaching an unpaired stimulus $(\mathrm{CS}-)$. Subjects then received lesions of the AcbC, $\mathrm{ACC}$, or CeA before being retested. AcbC lesions severely impaired performance; lesioned subjects approached the CS + significantly less often than controls, failing to discriminate between the CS + and CS -. ACC lesions also impaired performance but did not abolish discrimination entirely. CeA lesions had no effect on performance. Thus, the CeA is required for learning, but not expression, of a conditioned approach response, implying that it makes a specific contribution to the learning of stimulus-reward associations.
\end{abstract}

Environmental stimuli that are associated with rewarding events thereby gain motivational significance through Pavlovian conditioning processes. Appetitive conditioned stimuli (CSs) have many properties, among which is the ability to attract attention and elicit approach (Hearst \& Jenkins, 1974; Tomie, Brooks, \& Zito, 1989). This conditioned approach response often has the beneficial function of drawing animals (including humans) closer to sources of natural rewards, such as food, but it may also play a detrimental role in attracting humans toward artificial reinforcers such as drugs of abuse, maintaining addiction and inducing relapse (Altman et al., 1996; Robbins \& Everitt, 1999; Tiffany, 1990). For example,

Rudolf N. Cardinal, Guillaume Lachenal, Katherine M. Halkerston, Nung Rudarakanchana, Jeremy Hall, Caroline H. Morrison, Simon R. Howes, Trevor W. Robbins, and Barry J. Everitt, Department of Experimental Psychology, University of Cambridge, Cambridge, United Kingdom; John A. Parkinson, Department of Experimental Psychology and Department of Anatomy, University of Cambridge.

This work was supported by a Medical Research Council (MRC) Programme Grant to Barry J. Everitt, Trevor W. Robbins, and Anthony Dickinson and a Wellcome Trust Programme Grant to Trevor W. Robbins, Barry J. Everitt, Angela Roberts, and Barbara J. Sahakian and was conducted within the MRC Co-operative for Brain, Behaviour and Neuropsychiatry. Rudolf N. Cardinal was supported by the MRC and the University of Cambridge School of Clinical Medicine. Jeremy Hall was supported by Trinity College, Cambridge and the University of Cambridge School of Clinical Medicine. We thank Helen Sweet-Gossage for assistance with histological procedures.

Correspondence concerning this article should be addressed to Barry J. Everitt, Department of Experimental Psychology, University of Cambridge, Downing Street, Cambridge CB2 3EB, United Kingdom. E-mail: bje10@cus.cam.ac.uk individuals with a propensity to form and respond to Pavlovian stimulus-reward associations have been suggested to be more vulnerable to addictive drugs (Tomie, 1996). It is therefore important to understand the neural mechanisms by which animals learn associations between stimuli and rewards, and the manner in which such associations control behavior.

Autoshaping (Brown \& Jenkins, 1968) is a measure of Pavlovian stimulus-reward learning in which subjects approach a CS that predicts reward. In a typical autoshaping task designed for use with rats (Bussey, Everitt, \& Robbins, 1997), a visual stimulus (CS+) is presented on a computer screen and followed by delivery of food at a different location. A second stimulus $(\mathrm{CS}-)$ is also presented but never followed by food. Though the subject's behavior has no effect on food delivery, normal rats develop a conditioned response in which they selectively approach the food-predictive CS before returning to the food hopper to retrieve the primary reward. The autoshaped conditioned approach response is generally held to be under the control of Pavlovian, not instrumental, contingencies (Browne, 1976; Jenkins \& Moore, 1973; Mackintosh, 1974; Williams \& Williams, 1969), and this has been confirmed for the rat autoshaping task described (Bussey, Everitt, \& Robbins, 1997).

Autoshaping depends on several nodes of the limbic corticostriatal circuit, at the heart of which is the nucleus accumbens (Acb). The acquisition of autoshaping requires the nucleus accumbens core (AcbC; Parkinson, Willoughby, Robbins, \& Everitt, 2000), but also the anterior cingulate cortex (ACC; Bussey, Everitt, \& Robbins, 1997; Parkinson, Willoughby, et al., 2000), which projects to the AcbC (Brog, Salyapongse, Deutch, \& Zahm, 1993). Furthermore, a functional connection between the ACC and the AcbC is necessary for autoshaping to develop (Parkinson, Willoughby, et al., 2000). However, autoshaping does not depend upon the Acb shell (Parkinson, Willoughby, et al., 2000). The 
ACC appears to be the only direct limbic cortical afferent to the Acb that is required for autoshaping, as impairments are not seen after lesions of the basolateral amygdala (Parkinson, Robbins, \& Everitt, 2000), dorsal or ventral subiculum (Parkinson, Robbins, \& Everitt, 1996), medial prefrontal cortex (Bussey, Everitt, \& Robbins, 1997), or posterior cingulate cortex (Bussey, Everitt, \& Robbins, 1997). In addition, autoshaping acquisition requires the dopaminergic innervation of the Acb (Parkinson et al., in press) and the integrity of the central nucleus of the amygdala (CeA) (Parkinson et al., 2000)—although the CeA does not project directly to the AcbC or ACC (Brog et al., 1993; Pitkänen, 2000; Zilles \& Wree, 1995), it may regulate the dopaminergic projection from the midbrain to the AcbC (Everitt, Cardinal, Hall, Parkinson et al., 2000; Everitt et al., 1999; Parkinson, Cardinal, \& Everitt, 2000).

Although lesions of the AcbC, ACC, and CeA disrupt the acquisition of autoshaping, it is not known whether these structures contribute to learning of CS-US (or direct CS-response) associations, or to behavioral expression of learned associations, as a deficit in either would prevent an animal from displaying autoshaped responding. One way of addressing this issue is to examine the effects of lesions made after training. If a structure is solely involved in the learning of CS-US associations, a lesion of that structure should not affect performance in a well-trained animal. In contrast, such a lesion would be expected to disrupt performance if the structure were critical for storage or retrieval of CS-US associations, for the influence of Pavlovian CSs on locomotor behavior, or for locomotor behavior itself. Thus, the finding of a deficit in an animal trained preoperatively would indicate that the structure had a role in behavioral expression (though, of course, it might also have a role in learning). Similarly, given that the structure is required for acquisition, the lack of such a deficit would suggest that the structure had a specific role in learning, and not in the long-term storage of associations or in other aspects of performance - that is, implying the structure had a role in regulating the formation of an association within another site.

In the present study, therefore, rats were trained to an asymptotic level of performance on an autoshaping task before receiving excitotoxic lesions of the AcbC (Experiment 1), ACC (Experiment 2 ), or CeA (Experiment 3); they were subsequently retested on the same task. Preliminary reports of this work have appeared in abstract form (Cardinal, Lachenal, Parkinson, Robbins, \& Everitt, 2000; Everitt, Parkinson, Lachenal, et al., 2000).

\section{Experiment 1: Lesions of the AcbC}

\section{Method}

\section{Autoshaping Task}

Apparatus. The apparatus and task were described fully by Bussey, Everitt, and Robbins (1997). The apparatus consists of a testing chamber $(48 \mathrm{~cm}$ long $\times 30 \mathrm{~cm}$ high $\times 30 \mathrm{~cm}$ wide) with a display screen on one wall and a pellet dispenser located centrally in front of the display. Pressure-sensitive areas of floor $(14 \mathrm{~cm} \times 10 \mathrm{~cm})$ were located directly in front of the display, to the left and right of the dispenser, and centrally at the rear of the chamber. The apparatus was controlled by software written in BBC BASIC by Timothy J. Bussey, running on a BBC Master series computer.

Pretraining. Rats were first allowed to habituate to the test chamber and collect 45-mg food pellets (Rodent Diet Formula P, P. J. Noyes,
Lancaster, NH). Subjects were placed in the chamber for 5 min, with 4-5 pellets placed in and around the dispenser. After this, pellets were delivered on a variable-time $0-40$-s schedule for $15 \mathrm{~min}$.

Autoshaping. On the next day, rats were trained to associate stimuli with the delivery of pellets. Stimuli consisted of $8 \times 18$-cm white vertical rectangles displayed on the left and right of the screen for $10 \mathrm{~s}$. One was designated the $\mathrm{CS}+$ and the other the $\mathrm{CS}-$, and the stimuli were counterbalanced between subjects. A trial consisted of presentation of both the $\mathrm{CS}+$ and CS - in a randomized order. After a variable interval of 10-40 $\mathrm{s}$, the program waited for the rat to be located centrally at the rear of the chamber. One stimulus was then presented for $10 \mathrm{~s}$. The CS+ was always followed immediately by the delivery of food; the CS - was never followed by food. After this, another variable interval followed, the program waited for the rat to return to the rear of the chamber, and the other stimulus was presented.

When a stimulus was presented, activation of one of the two floor panels in front of the screen was scored as an approach, and no further approaches were scored during that stimulus presentation. Rats were trained for a total of 100 trials ( 2 days with 50 trials per day). Approaches to the CS + and the CS - were scored in blocks of 10 trials, and mean approach latency was calculated over 100 trials (Bussey, Everitt, \& Robbins, 1997). Data were analyzed as CS+/CS - approach scores, as difference scores (CS + approaches - CS - approaches; after Bussey, Everitt, \& Robbins, 1997) and as the ratio $[(\mathrm{CS}+$ approaches $) \div(\mathrm{CS}+$ approaches $+\mathrm{CS}-$ approaches $)]$, a measure of stimulus discrimination that is relatively independent of absolute approach activity.

\section{Subjects and Overview}

Twenty-eight experimentally naive male hooded Lister rats (HarlanOlac UK Ltd, Bicester, UK; free-feeding weight, 316-420 g) were housed in pairs under a 12-hr reversed light-dark cycle (lights off from 0830 to 2030). All experimental procedures were subject to UK Home Office approval (Project Licenses PPL 80/00684 and PPL 80/1324). Subjects were maintained at $80-90 \%$ of their free-feeding body weight and were trained for 100 trials on the autoshaping task described above. Subjects that failed to approach the CS+ twice as frequently as the CS - on the last 30 trials of training were given a further 30 or 60 remedial trials; if they failed to meet this criterion on the last 30 remedial trials, they were excluded from the experiment. The successful subjects were given free access to food and randomly assigned to groups that received lesions of $\mathrm{AcbC}$ or sham lesions (with the criterion that the groups be matched for the number of training trials). After a recovery period of 5 days, during which they had free access to food, they were returned to the food-deprivation regimen. Their performance on the same autoshaping task was tested for a further 50 trials.

\section{Surgery}

The subjects were anesthetized with Avertin (2\% [wt/vol] 2,2,2-tribromoethanol, $1 \%$ [wt/vol] 2-methylbutan-2-ol, and $8 \%$ [vol/vol] ethanol in phosphate-buffered saline, $10 \mathrm{ml} / \mathrm{kg}$ ip) and placed in a stereotaxic frame (David Kopf Instruments, Tujunga, CA). The skull was exposed, and a dental drill was used to remove the bone directly above the injection and cannulation sites. The dura mater was broken with the tip of a needle, avoiding damage to underlying venous sinuses. Lesions and cannulation were performed in accordance with the atlas of Paxinos and Watson (1996), using bregma as the origin, with the incisor bar set at $3.3 \mathrm{~mm}$ below the interaural line.

Fiber-sparing excitotoxic lesions were made with $0.09 \mathrm{M}$ quinolinic acid (Sigma, Poole, UK) in $0.1 \mathrm{M}$ phosphate buffer (final $\mathrm{pH}=7.2-7.4$ ) injected through a glass micropipette (tip diameter 50-100 $\mu \mathrm{m}$ ) glued to the tip of a 1- $\mu$ l syringe (SGE Ltd, Milton Keynes, UK); the syringe was hand-driven during infusions. Lesion coordinates (in millimeters from the skull surface at bregma) were $\mathrm{AP}+1.2, \mathrm{ML} \pm 1.8, \mathrm{DV}-7.1$. At each 
site, $0.5 \mu 1$ of toxin was infused over 3 min, after which 2 min was allowed for diffusion before the injector was removed. Sham lesions were made in the same manner, except that vehicle was infused. Postoperatively, subjects were left for 5-7 days to recover, with free access to food, after which food restriction was resumed.

\section{Histological Assessment}

At the end of the experiment, subjects were deeply anesthetized with Euthatal (pentobarbitone sodium, $200 \mathrm{mg} / \mathrm{ml},>1.5 \mathrm{ml}$ ip) and perfused transcardially with $0.01 \mathrm{M}$ phosphate-buffered saline followed by $4 \%$ (wt/vol) paraformaldehyde in phosphate-buffered saline. Their brains were removed and postfixed in paraformaldehyde before being dehydrated in $20 \%$ (wt/vol) sucrose; they were then sectioned coronally at $60 \mu \mathrm{m}$ thickness on a freezing microtome, and every third section was mounted and allowed to dry. Sections were passed through a series of ethanol solutions of descending concentration (3 min in each of 100\%, 95\%, and $70 \%$ [vol/vol] ethanol in water) and stained for $\sim 5 \mathrm{~min}$ with cresyl violet ( $0.05 \%$ [wt/vol] aqueous cresyl violet, $2 \mathrm{mM}$ acetic acid, and $5 \mathrm{mM}$ formic acid in water). After staining, sections were rinsed in water and $70 \%$ ethanol before being differentiated in 95\% ethanol. Finally, they were dehydrated and delipidated in $100 \%$ ethanol and Histoclear (National Diagnostics, Hessle, UK) before being cover-slipped and allowed to dry. The sections were used to verify lesion placement and assess the extent of lesion-induced neuronal loss and gliosis.

\section{Data Analysis}

Data collected by the control programs were imported into a relational database (Microsoft Access 97) and analyzed with SPSS 9, using principles based on Howell (1997). Data were subjected to analysis of variance (ANOVA) using a general linear model and the SPSS Type III sum-ofsquares method. All tests of significance were performed at $p=.05$; full factorial models were used unless otherwise stated. Homogeneity of variance was verified with Levene's test. ANOVA models are described by using a form of Keppel's (1982) notation, that is, dependent variable $=$ $A_{2} \times\left(B_{5} \times S\right)$ where $A$ is a between-subjects factor with two levels and $B$ is a within-subjects factor with five levels; $S$ denotes subjects. For repeated measures analyses, Mauchly's test of sphericity of the covariance matrix was applied, and the degrees of freedom were corrected to more conservative values by using the Huynh-Feldt epsilon (Huynh \& Feldt, 1970) for any terms involving factors in which the sphericity assumption was violated; corrected degrees of freedom are reported to 1 decimal place. Significant main effects of interest were investigated with pairwise comparisons with a Sidak correction. Where significant interactions were found after repeated measures analysis, a pooled error term was used to test between-subjects simple effects of a priori interest, but separate error terms (i.e., one-way ANOVA) were used for within-subjects factors (Howell, 1997, p. 468).

\section{Results}

Six rats failed to reach the training criterion. Fourteen received AcbC lesions, and 8 received sham lesions. Five rats in the AcbC group were excluded because their lesions were incomplete or too extensive, and data from 1 rat in the sham group was excluded because of mechanical failure of the apparatus during testing; final group sizes were therefore $n=9$ (AcbC) and $n=7$ (sham). Figure 1 presents schematics showing the largest and smallest extent of the lesions, which produced almost complete bilateral destruction of the AcbC. Photomicrographs of lesions using the same parameters have been presented previously (Parkinson, Olmstead, Burns, Robbins, \& Everitt, 1999; Parkinson, Willoughby, et al., 2000).

\section{Preoperative Acquisition}

Both groups reached the same asymptote of performance before surgery (see Figures $2 \mathrm{~A}-2 \mathrm{C}$ ). The difference scores for the last three blocks of preoperative training (10 trials per block) were analyzed with the model Group $_{2} \times\left(\right.$ Block $\left._{3} \times S\right)$; this revealed a Group $\times$ Block interaction, $F(1.6,23.1)=4.10, \tilde{\varepsilon}=.824, p=$ .037 , as well as a main effect of block, $F(1.6,23.1)=5.39, \tilde{\varepsilon}=$ $.824, p=.016$. However, comparison of the difference scores for the final block of training showed no difference between the groups: one-way ANOVA, $F(1,14)=1.35, n s$. By chance, therefore, the two groups were acquiring the task at different rates preoperatively, but they reached the same eventual level of performance before surgery (see Figure 2).

\section{Postoperative Performance}

Lesions of the AcbC severely and persistently impaired performance of the autoshaping task (see Figures 2A-2C). Difference scores were analyzed with the model Group $_{2} \times\left(\right.$ Block $\left._{5} \times S\right)$; this revealed a main effect of group, $F(1,14)=9.37, p=.008$. The block and Group $\times$ Block terms were not significant $\left(F_{\mathrm{s}}<1\right)$. Similarly, analysis of ratio scores revealed an impairment: group, $F(1,14)=6.25, p=.025$; block and Group $\times$ Block $(F \mathrm{~s}<1.15$, $n s)$. Despite this significant deficit in appetitive behavior, primary consummatory behavior was unaffected: at no point did any rat fail to consume all the pellets.

AcbC-lesioned subjects failed to discriminate between the CS+ and $\mathrm{CS}-$. Analysis of raw approach scores using the model Group $_{2} \times\left(\right.$ Stimulus $_{2} \times$ Block $\left._{5} \times S\right)$ revealed a Stimulus $\times$ Group interaction, $F(1,14)=9.37, p=.008$. Subgroup analysis showed that the sham-lesioned rats showed discrimination between the stimuli: main effect of stimulus, $F(1,6)=44.4, p=.001$, but the core-lesioned subjects did not: stimulus, $F(1,8)=3.21, p=.111$; Stimulus $\times$ Block $(F<1, n s)$.

The failure of discrimination in AcbC-lesioned subjects was due to a specific deficit in approaches to the CS + . To characterize the nature of the deficit, $\mathrm{CS}+$ and $\mathrm{CS}-$ approach scores were analyzed separately, by using the model Group $_{2} \times\left(\right.$ Block $\left._{5} \times S\right)$ in each case. This revealed that AcbC-lesioned subjects approached the CS + significantly less frequently than shams: main effect of group, $F(1,14)=5.73, p=.031$, and this difference did not alter with further experience: Group $\times$ Block and block, $F$ s $<1$. There was no significant difference between the groups in the frequency of CS - approaches: group, $F(1,14)=1.54$; Group $\times$ Block, $F<1$, though this frequency declined over time across groups: main effect of block, $F(4,56)=4.49, p=.003$.

When lesioned rats did approach the stimuli, their approach latencies did not differ from sham-operated rats (see Figure 2D). Mean latencies to approach each stimulus were calculated across all postoperative trial blocks and analyzed with the model Group $_{2} \times\left(\right.$ Stimulus $\left._{2} \times S\right)$. This showed that the CS + was approached faster than the CS - : stimulus, $F(1,13)=5.07, p=$ .042 , but the group differences did not reach significance: group, $F(1,13)=3.35, p=.09$; Group $\times$ Block, $F(1,13)=1.23$.

\section{Summary}

AcbC lesions produced a severe, persistent impairment in performance of the autoshaped response; lesioned subjects ap- 

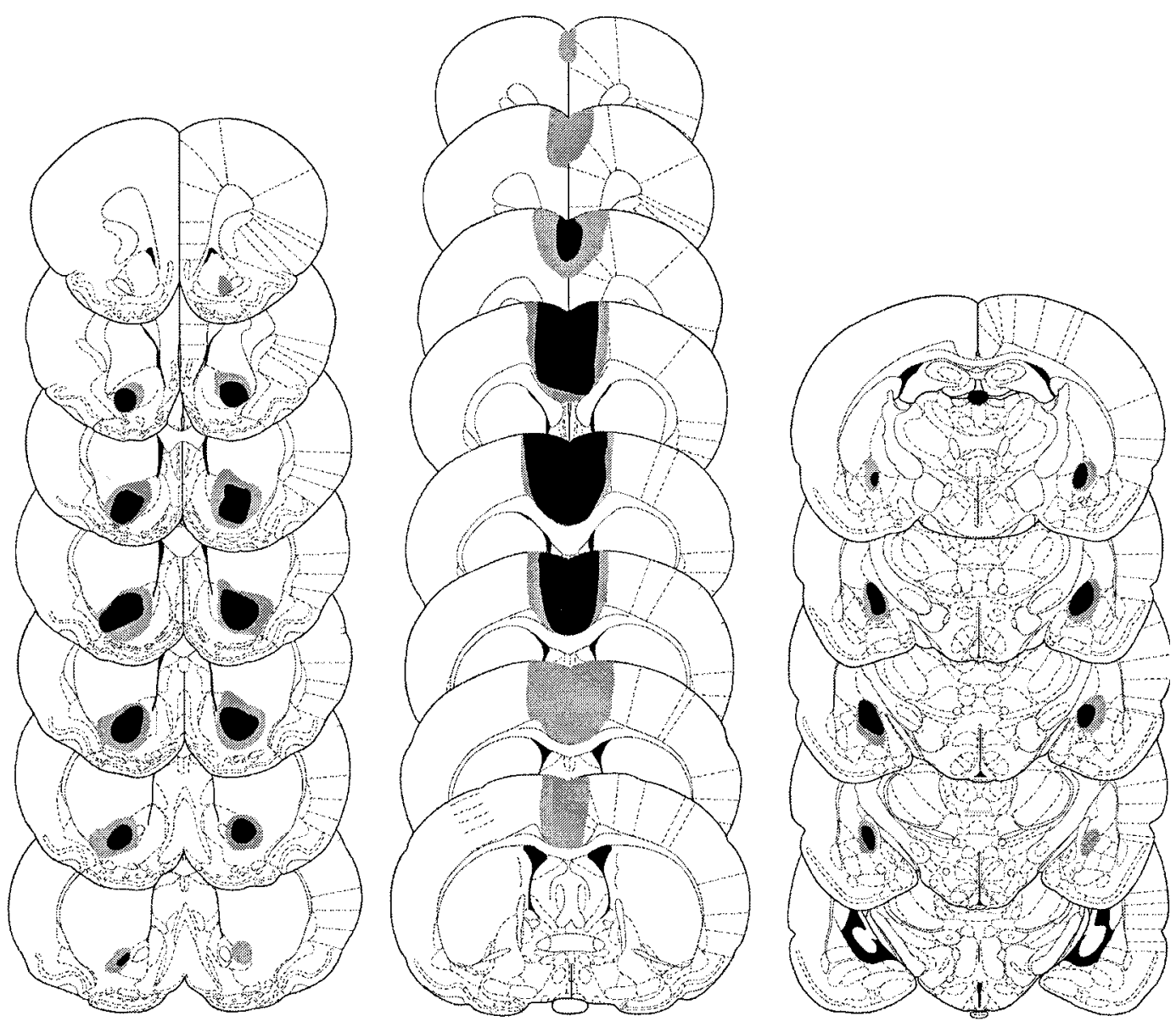

Figure 1. Schematic of lesions of the nucleus accumbens core (AcbC, left column), anterior cingulate cortex (ACC, middle column), and central nucleus of the amygdala (CeA, right column). Black shading indicates the extent of neuronal loss common to all subjects; gray shading indicates the area lesioned in at least 1 subject. Coronal sections are $+2.7 \mathrm{~mm}$ through $+0.48 \mathrm{~mm}$ (AcbC), $+3.2 \mathrm{~mm}$ through $-0.3 \mathrm{~mm}$ (ACC), and $-1.8 \mathrm{~mm}$ through $-3.8 \mathrm{~mm}(\mathrm{CeA})$ relative to bregma. From The Rat Brain in Stereotaxic Coordinates (4th ed., Figures 8-19 and 27-34), by G. Paxinos and C. Watson, 1998, San Diego, CA: Academic Press. Copyright 1998 by Academic Press. Adapted with permission.

proached the CS + significantly less often than did controls, failing to discriminate between the $\mathrm{CS}+$ and the $\mathrm{CS}-$.

\section{Discussion}

The present results clearly establish a role for the AcbC in performance of a well-learned conditioned approach response. The failure of AcbC-lesioned rats to discriminate between $\mathrm{CS}+$ and $\mathrm{CS}-$ was not secondary to changes in locomotor activity. AcbClesioned rats are hyperactive (Parkinson et al., 1999), yet in the present experiment, they approached the CS + less often than controls. Thus, the lesion induced a highly specific deficit, selectively impairing conditioned approach behavior.

This finding is compatible with the view that the Acb mediates the impact of Pavlovian CSs on locomotor and instrumental behavior (Parkinson, Cardinal, \& Everitt, 2000). The AcbC is required for autoshaping, which may contribute to instrumental responding if the Pavlovian CS is located near the instrumental manipulandum, or hinder it if the CS is located elsewhere. The
AcbC is also required for Pavlovian CSs to exert a different motivational effect on instrumental responding, namely Pavlovian-instrumental transfer (Hall, Parkinson, Connor, Dickinson, \& Everitt, 2001), an effect through which a CS (which may be poorly localized in space and therefore not approachable) can enhance instrumental responding if the CS predicts a motivationally relevant unconditioned stimulus (US; Balleine, 1994; Dickinson, 1994; Dickinson \& Dawson, 1987). Thus, although the nucleus accumbens was accurately described by Mogenson, Jones, and Yim (1980) as a limbic-motor interface, it may also be considered a Pavlovian-instrumental interface in that it is a critical site for the motivational and directional impact of Pavlovian CSs on instrumental responding (Balleine \& Killcross, 1994; Hall et al., 2001) and locomotor approach (Parkinson, Cardinal, \& Everitt, 2000; Parkinson, Robbins, \& Everitt, 1996; Parkinson, Willoughby, et al., 2000). In particular, selective AcbC lesions abolish Pavlovian conditioned approach in all tasks that have explicitly measured it 
A

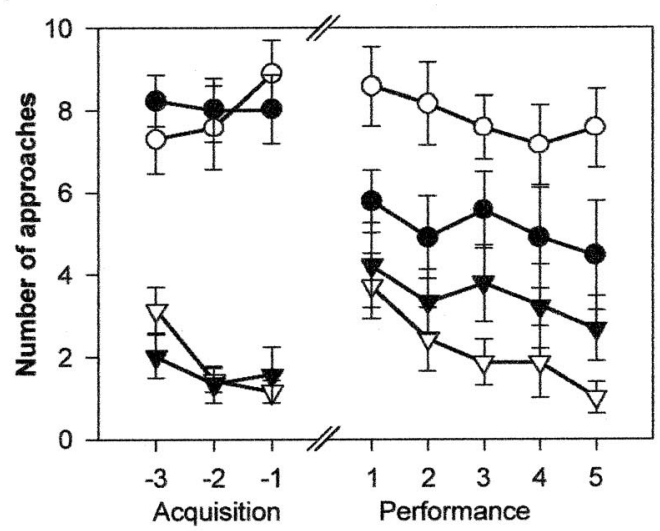

Trial block

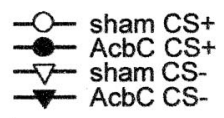

C

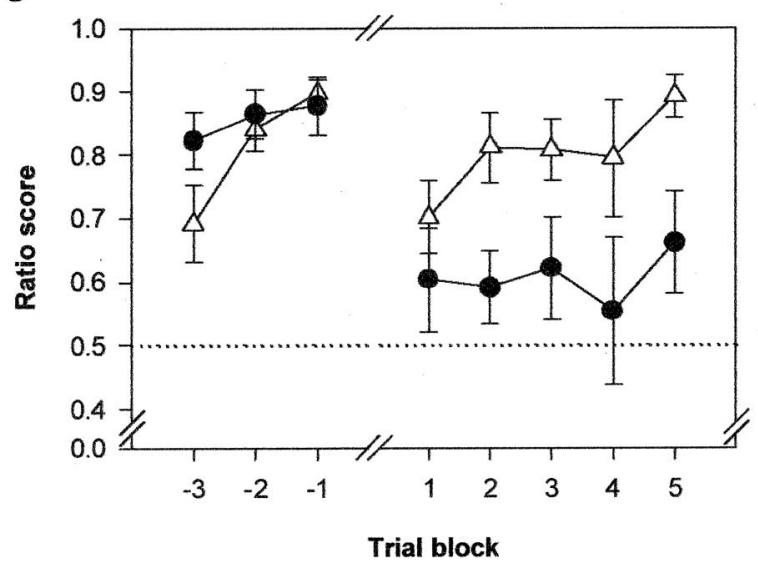

B

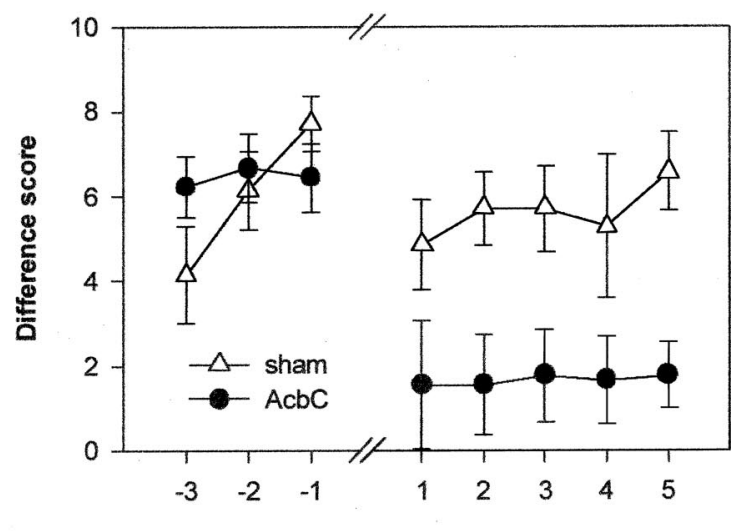

Trial block

D

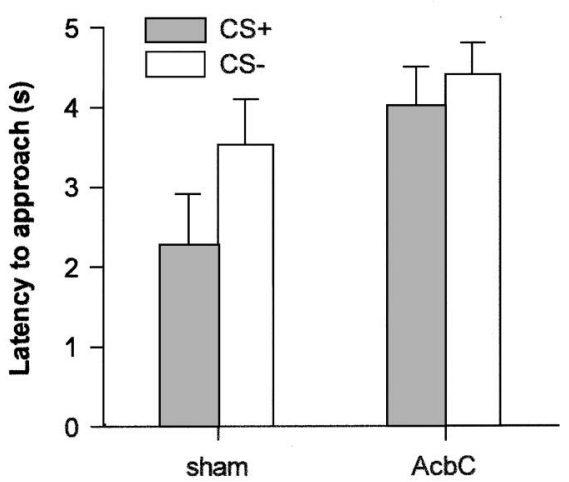

Figure 2. Lesions of the nucleus accumbens core (AcbC) impaired autoshaping performance when those lesions were made after training. The final three sessions of preoperative acquisition training are shown, together with postoperative performance. A: Approaches to the paired conditioned stimulus $(\mathrm{CS}+)$ and the unpaired stimulus $(\mathrm{CS}-)$. B: Difference scores (CS + approaches $-\mathrm{CS}-$ approaches). C: Discrimination ratio scores $[(\mathrm{CS}+$ approaches $) \div(\mathrm{CS}+$ approaches $+\mathrm{CS}-$ approaches $)]$. D: Latencies to approach each stimulus. Data are means $( \pm S E M)$.

(Parkinson et al., 1999; Parkinson, Willoughby, et al., 2000; present study).

As the AcbC is part of the circuit mediating behavioral expression of conditioned approach, it is difficult to establish whether it also has a role in learning. It might be possible to answer this question, for example, by inactivating the AcbC temporarily while $\mathrm{CS}$-US pairings are given; if the AcbC is not required for learning, such inactivation might be expected to reveal latent learning (i.e., a savings effect, in that the subject subsequently performs better than it would if no training had been given).

One task that has been used to investigate the role of the AcbC in learning is free-operant instrumental conditioning (Kelley, SmithRoe, \& Holahan, 1997). However, instrumental conditioning is complicated by the fact that performance of the instrumental response is part of the learning process (because responding is required in order to expose the subject to the instrumental actionoutcome contingency). Though it has been observed that blockade of $N$-methyl-D-aspartate (NMDA)-type glutamate receptors in the AcbC with DL-2-amino phosphonovaleric acid (AP-5) prevents the acquisition of an instrumental response (Kelley et al., 1997) but has no effect on the performance of a previously learned response, it has also been shown that excitotoxic lesions of the AcbC do not prevent rats from acquiring a new instrumental response (though the effects of amphetamine on responding are altered; Parkinson et al., 1999), and that lesions of the whole Acb do not prevent rats from detecting instrumental contingencies (though they reduce asymptotic levels of performance; Balleine \& Killcross, 1994). There are three explanations that may resolve this apparent discrepancy. First, it is possible that instrumental learning normally occurs within the AcbC, and so is disrupted by NMDA receptor blockade, but when the AcbC is destroyed other circuits act to compensate. There is at present no evidence to support this suggestion, and it is not parsimonious; furthermore, it is not obvious why these hypothesized other circuits could not learn when the 
AcbC is inactivated only temporarily (as by AP-5). Therefore, this seems an unlikely explanation. Second, blockade of NMDA receptors in the AcbC might disrupt ongoing neuronal activity in the $\mathrm{AcbC}$ and thereby interfere with the functions of brain regions that are responsible for instrumental learning, such as the prelimbic cortex (Balleine \& Dickinson, 1998). Total destruction of the AcbC might not have the same effect. This suggestion is plausible, but again there is no direct evidence for it. Third, Acb lesions induce a motivational deficit, probably by impairing Pavlovian conditioned motivation (Balleine \& Killcross, 1994; Parkinson, Cardinal, \& Everitt, 2000). It may therefore be that NMDA receptor blockade in the AcbC prevents instrumental learning by interfering with a motivational process that normally assists learning. Specifically, as intra-AcbC AP-5 impaired approach to the alcove where food was delivered in the study of Kelley et al. (1997), it may be that subjects were not exposed to the reinforcer as often, or as soon after the instrumental response, as were control subjects. Even small response-reinforcer delays have a profoundly disruptive effect on instrumental learning (Dickinson, Watt, \& Griffiths, 1992). Once subjects had been trained, AP-5 had no effect on performance (Kelley et al., 1997). As this discussion makes clear, this indicates that the AcbC normally makes a contribution to instrumental learning, but it may do so by permitting learning to occur in other systems, rather than being the site of learning itself.

In the context of Pavlovian learning, it appears that the AcbC makes a direct contribution both to learning and performance. The present data show that the $\mathrm{AcbC}$ is required for the performance of an autoshaped conditioned response. However, it has also been shown that glutamate and dopamine (DA) receptors in the AcbC contribute to the acquisition of autoshaping. Di Ciano, Cardinal, Cowell, Little, and Everitt (2001) recently found that infusion of the NMDA receptor antagonist AP-5 into the AcbC impaired the acquisition, but not the performance, of autoshaping (whereas the AMPA/kainate-type glutamate receptor antagonist LY293558 had the opposite effect, disrupting performance but not learning). The mixed DA receptor antagonist $\alpha$-flupenthixol blocked acquisition completely but impaired performance to a lesser degree (Di Ciano et al., 2001); similarly, DA depletion of the whole Acb produces a profound deficit in autoshaping acquisition and a smaller deficit in performance (Parkinson et al., in press). Thus, DA and NMDAtype glutamate receptors in the AcbC appear to play a specific role in learning the autoshaped approach response (Di Ciano et al., 2001; Parkinson et al., in press).

In summary, the precise role of the AcbC in learning is presently unclear, but the present results demonstrate clearly that it is involved in the behavioral expression of well-learned conditioned approach responses. The autoshaping task used in the present experiments may lend itself well to further study of the AcbC's contribution to learning, as autoshaping may be acquired even if the subject cannot approach the CS during training (Moore, 1973).

\section{Experiment 2: Lesions of the ACC}

\section{Method}

Twenty-eight male hooded Lister rats were maintained at $90 \%$ of their free-feeding body weight and trained for 100 trials as described in Experiment 1 . Subjects that failed to approach the CS+ on at least $70 \%$ of the last 30 trials were given a further 50 remedial trials; if they failed to meet the same criterion on the last 30 remedial trials, they were then excluded from the experiment. The successful subjects were given free access to food and randomly assigned to groups that received sham lesions or lesions of peri- and postgenual ACC (targeting Cingulate Area $\mathrm{Cg} 2$, and all of $\mathrm{Cg} 1$ superior to $\mathrm{Cg} 2$, but not including more anterior parts of $\mathrm{Cg} 1$, in accordance with the atlas of Paxinos \& Watson, 1998); at the time of operation, subjects weighed 274-408 g. Surgical methods were as for Experiment 1, except that ACC lesions were made with a 28-gauge stainless steel cannula (diameter $=0.36 \mathrm{~mm}$ external, $0.18 \mathrm{~mm}$ internal) attached by polyethylene tubing to a 10- $\mu$ l syringe (Hamilton Bonaduz AG, Bonaduz, Switzerland) mounted on a Harvard Apparatus (Edenbridge, UK) infusion pump; lesion coordinates were AP $+1.2, \mathrm{ML} \pm 0.5, \mathrm{DV}-3.0$ and -2.2 ; $\mathrm{AP}+0.5$, ML $\pm 0.5, \mathrm{DV}-2.8$ and $-2.0 ; \mathrm{AP}-0.2, \mathrm{ML} \pm 0.5, \mathrm{DV}-2.5$ and $-2.0(0.5 \mu \mathrm{l}$ per site, infused over $1 \mathrm{~min}$ ). After recovery, the rats were returned to the food-deprivation regimen. Their performance on the same autoshaping task was tested for a further 50 trials.

\section{Probe Test}

Next, a probe test was performed, consisting of 20 trials in which the $\mathrm{CS}+$ and CS - were presented simultaneously for $10 \mathrm{~s}$ and approaches were measured. Food was not delivered, so this test constituted an extinction trial to the $\mathrm{CS}+$, whereas the $\mathrm{CS}-$ was still a perfect predictor of food absence. The probe test was intended to be a more sensitive test than the standard autoshaping task (in which the subject might form CS-US associations perfectly and yet approach all stimuli), as it forced the subject to make a choice between the $\mathrm{CS}+$ and the $\mathrm{CS}-$.

\section{Locomotor Test}

Finally, locomotor activity was measured in wire mesh cages $(25 \mathrm{~cm}$ long $\times 40 \mathrm{~cm}$ wide $\times 18 \mathrm{~cm}$ high). The cages were equipped with two horizontal photocell beams situated $1 \mathrm{~cm}$ from the floor that enabled movements along the long axis of the cage to be registered. Subjects were placed in these cages, which were initially unfamiliar to them, and their activity was recorded for $2 \mathrm{hr}$. All subjects were tested in the food-deprived state.

\section{Results}

Eight subjects failed to reach the performance criterion. Thus, despite the use of a slightly different performance criterion for Experiments 2 and 3 compared with Experiment 1, a similar proportion of subjects met the criterion, and preoperative performance was extremely similar (see below). Of those subjects that reached the criterion, 11 received ACC lesions and 9 subjects received sham lesions. There were two postoperative deaths in the sham group. Exploratory data analysis revealed that 1 subject in the sham group was an outlier (complete absence of approach behavior on two consecutive sessions with data points consistently $>2 S D$ from the group mean); this subject was excluded from analysis. Histological analysis revealed that all lesions were correctly sited, so the final group sizes were 11 (ACC lesioned) and 6 (sham).

\section{Histology}

Neuronal loss and associated gliosis in the ACC-lesioned subjects extended from $\sim 2.5 \mathrm{~mm}$ anterior to bregma to $\sim 0.3 \mathrm{~mm}$ posterior to bregma, destroying perigenual $\mathrm{Cg} 1$ and $\mathrm{Cg} 2$; there was very slight damage to the dorsal prelimbic cortex in a few subjects and no damage to the infralimbic or posterior cingulate cortex. 
Figure 1 presents schematics showing the largest and smallest extent of the lesions; photomicrographs of such lesions have been presented previously (Bussey, Muir, Everitt, \& Robbins, 1996; Bussey, Robbins, \& Everitt, 1997; Parkinson, Willoughby, et al., 2000).

\section{Preoperative Acquisition}

Both groups reached the same asymptote of performance preoperatively (see Figures 3A-3C). The difference scores for the last three blocks of training (10 trials per block) were analyzed with the model Group $_{2} \times\left(\right.$ Block $\left._{3} \times S\right)$; there were no significant effects of group, $F(1,15)=1.67$; block, $F(1.5,23.0)=2.73, \tilde{\varepsilon}=.766, p=$ .098; or Group $\times$ Block $(F<1)$.

\section{Postoperative Performance}

Lesions of the ACC significantly impaired the performance of the autoshaped response (see Figures $3 \mathrm{~A}-3 \mathrm{C}$ ). Analysis of the postoperative difference scores using the model Group $_{2} \times$ $\left(\right.$ Block $\left._{5} \times S\right)$ revealed a significant main effect of group, $F(1$, $15)=7.77, p=.014$, reflecting poorer discrimination in the ACC-lesioned group; there was also a significant effect of block, $F(4,60)=3.52, p=.012$, but no interaction $(F<1, n s)$. This impairment was also evident after analysis of ratio scores, which also revealed an effect of group, $F(1,15)=5.73, p=.03$, and block, $F(4,60)=5.14, p=.001$. Although Figures $3 \mathrm{~B}$ and $3 \mathrm{C}$ suggest some recovery in the ACC-lesioned group, there was no Block $\times$ Group interaction, $F(4,60)=1.18$, ns. Primary consummatory behavior was unaffected by the lesion: At no point did any rat fail to consume all the pellets.

Further analysis demonstrated that this deficit was attributable to a persistent deficit in $\mathrm{CS}+$ approach in the ACC-lesioned group. Postoperative CS + and CS - approach scores were analyzed separately with the model Group $_{2} \times\left(\right.$ Block $\left._{5} \times S\right)$ in each case. These analyses showed that the ACC-lesioned group made significantly fewer approaches to the $\mathrm{CS}+$ : main effect of group, $F(1$, $15)=5.22, p=.037$, an effect that did not alter across testing (terms involving block, $F \mathrm{~s}<1, n s$ ). The two groups did not differ in their approaches to the CS - : group, $F(1,15)=2.15$, ns; both groups showed an equivalent decline in $\mathrm{CS}-$ responding: block, $F(4,60)=6.46, p<.001$; Block $\times$ Group, $F(4,60)=1.11$, ns. It is this decline in $\mathrm{CS}-$ responding that caused a degree of recovery of discriminative performance, evident as an improvement in difference and ratio scores, though the ACC-lesioned group remained impaired throughout testing.

Although these analyses did not demonstrate that the groups recovered at different rates, it was certainly the case that the ACC-lesioned group recovered to some extent (on all measures of performance) and did discriminate between the two stimuli. An improvement in discrimination scores was apparent for the ACClesioned group: main effects of block for difference scores, $F(4$, $40)=3.83, p=.01$; for ratio scores, $F(4,40)=5.92, p=.001$. Similarly, analysis of absolute approach scores in the ACClesioned group demonstrated a main effect of stimulus, $F(1$, $10)=28.5, p<.001$; block, $F(4,40)=3.98, p=.008$; and a Stimulus $\times$ Block interaction, $F(4,40)=3.83, p=.01$. No such improvement was detectable in the sham group, which performed well throughout: no block effects for the discrimination scores, maximum $F(4,20)=1.68, n s$; or Stimulus $\times$ Block interaction for absolute approach scores, $F(4,20)=1.21$, ns.

Lesioned rats were slower to approach both stimuli (see Figure 3D). Mean latencies to approach each stimulus were calculated across all postoperative trial blocks and analyzed with the model Group $_{2} \times\left(\right.$ Stimulus $\left._{2} \times S\right)$. This revealed a main effect of group, $F(1,15)=5.64, p=.031$, with the ACC-lesioned group showing longer approach latencies, and a main effect of stimulus, $F(1$, $15)=15.5, p=.001$, as subjects approached the CS+ faster than the $\mathrm{CS}-$. There was no Stimulus $\times$ Group interaction, $F(1$, 15) $=1.41, n s$.

\section{Probe Test}

ACC-lesioned subjects showed reduced discrimination in the probe test (see Figure 3E). A discrimination ratio was calculated as the number of trials on which the CS + was approached divided by the number of trials on which either stimulus was approached. Analysis of this measure by one-way ANOVA revealed an impairment in the ACC-lesioned group, $F(1,15)=4.57, p=.049$, though, in principle, this may be attributable to a group difference in responding to the novelty of simultaneous $\mathrm{CS}+/ \mathrm{CS}-$ presentation, as well as to an impairment in discrimination itself. Despite the impairment, both groups discriminated between the CS + and CS-: sham group compared to $50 \%$ discrimination ratio by onesample $t$ test, $\mathrm{t}(5)=22.1, p<.001$; ACC-lesioned group, $t(10)=9.52, p<.001$.

\section{Locomotor Test}

One rat in the ACC-lesioned group fell ill after the autoshaping tests and was perfused; thus, final group numbers for the locomotor test were 10 (ACC-lesioned) and 6 (sham).

There was no clear pattern of difference in locomotor activity between sham and ACC-lesioned groups (see Figure 3F), although there were statistical differences in the pattern of habituation to novelty. Beam-break data were subjected to a square-root transformation and analyzed with the model $\operatorname{Group}_{2} \times\left(\operatorname{Bin}_{12} \times S\right)$. There was no main effect of group $(F<1, n s)$, but in addition to the main effect of bin, $F(8.5,118.9)=27.5, \tilde{\varepsilon}=.772, p<.001$, reflecting habituation, there was a Bin $\times$ Group interaction, $F(8.5$, $118.9)=3.48, \tilde{\varepsilon}=.772, p=.001$. The only bin for which a simple effect was significant in its own right was the bin that was completed $70 \mathrm{~min}$ into the session: simple effect of group for this bin, $F(1,14)=5.21, p=.039$, but elimination of this bin left the interaction term still significant, $F(7.6,106.8)=2.88, \tilde{\varepsilon}=.763$, $p=.007$. Inspection of Figure $3 \mathrm{~F}$ suggests that this may have been due to slight hyperactivity in the ACC-lesioned group late in the session. There was no evidence of hypoactivity in the ACClesioned group; thus, changes in locomotor activity cannot account for the deficit observed during autoshaping.

\section{Summary}

ACC lesions impaired autoshaping performance, persistently reducing the frequency with which the $\mathrm{CS}+$ was approached. Lesioned subjects were also slower to approach both stimuli, but neither effect was attributable to a reduction in spontaneous loco- 
A

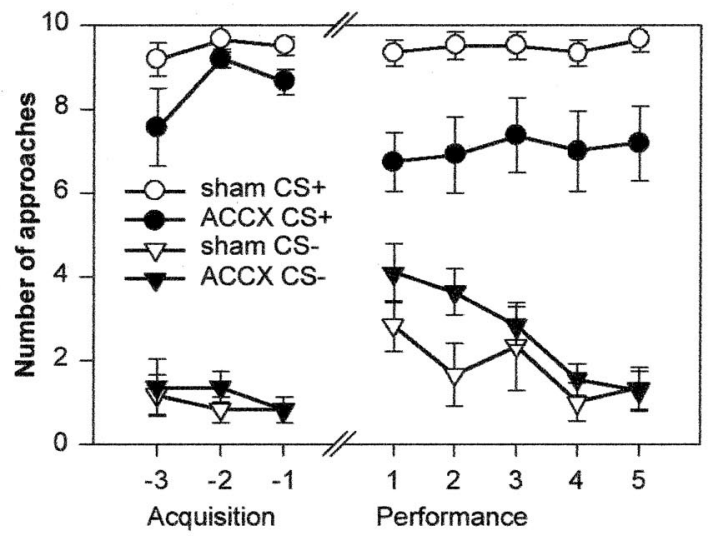

Trial block

C

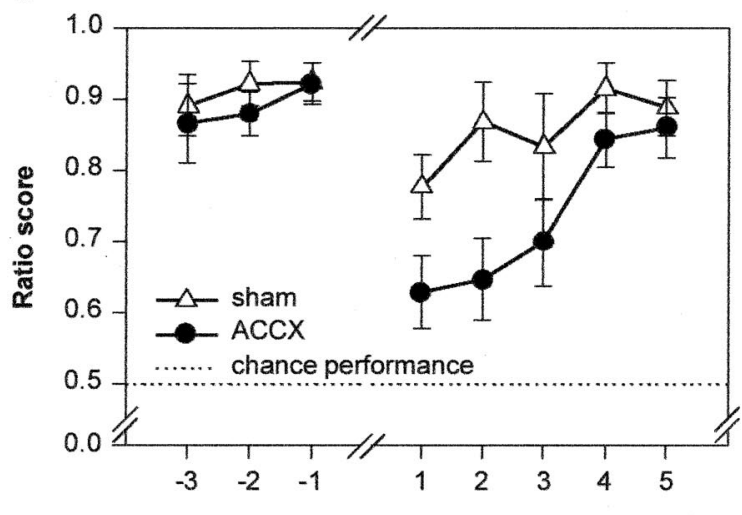

Trial block

E

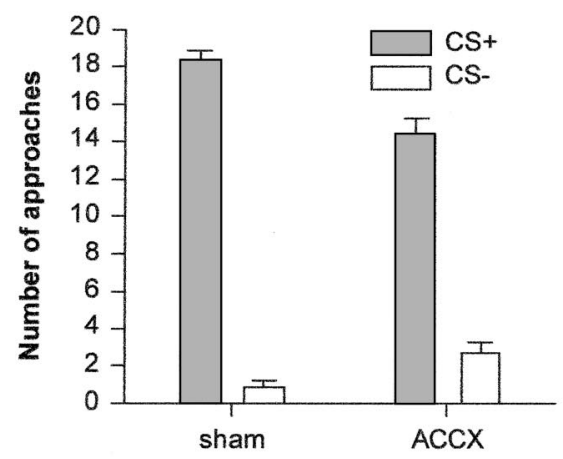

B

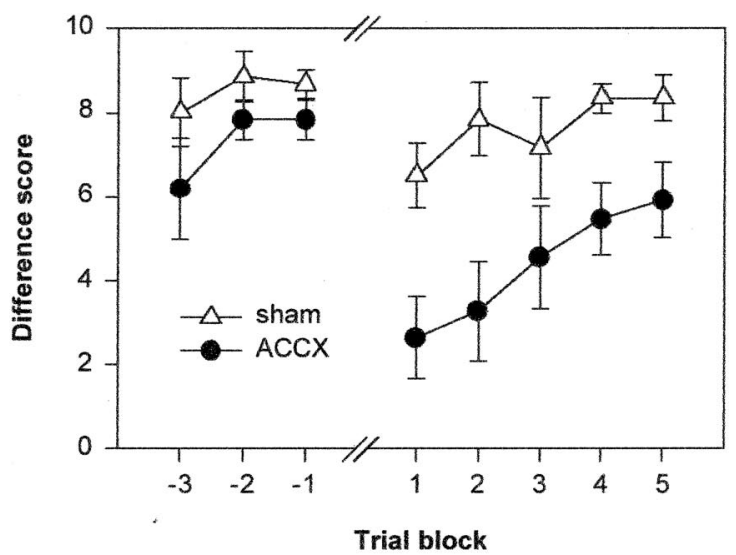

D

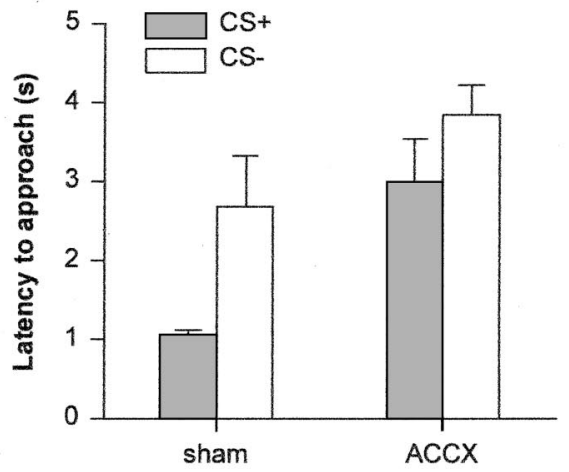

F

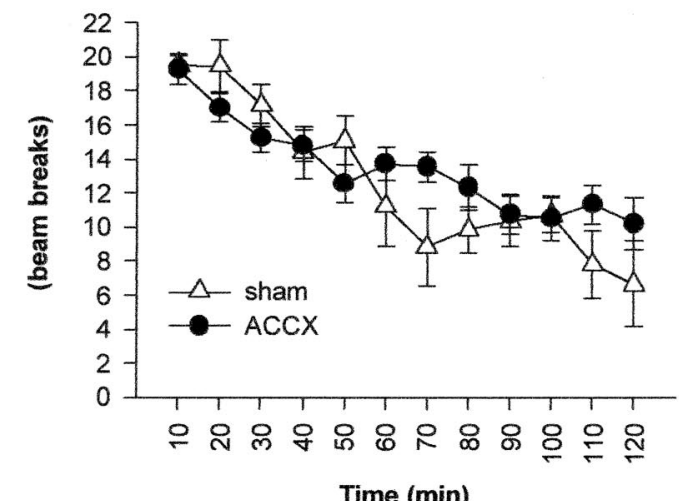

Figure 3. Posttraining lesions of the anterior cingulate cortex (ACCX) impaired the performance of autoshaping. The final three sessions of preoperative acquisition training are shown, together with postoperative performance. A: Approaches to the paired conditioned stimulus $(\mathrm{CS}+)$ and the unpaired stimulus $(\mathrm{CS}-)$. B: Difference scores. C: Discrimination ratio scores. D: Latencies to approach each stimulus postoperatively. The ACC-lesioned group approached more slowly. E: Autoshaping probe test, showing reduced CS+/CS - discrimination in ACC-lesioned rats. (Note that approaches to the CS + and CS - are mutually exclusive on any given trial.) F: Locomotor activity in a novel environment, illustrating that the autoshaping deficit in ACC-lesioned rats was not attributable to locomotor hypoactivity. Data are means ( \pm SEM). 
motor activity. A impairment in $\mathrm{CS}+/ \mathrm{CS}-$ discrimination was also apparent in the probe test. Though an impairment persisted throughout testing, a degree of discriminative ability was retained by ACC-lesioned rats, and limited recovery occurred.

\section{Discussion}

These results indicate a role for the ACC in performance of a conditioned approach response previously learned to asymptote, consistent with the suggestion that the ACC plays an important role in tasks based on stimulus-reinforcer associations (Buchanan \& Powell, 1982; Bussey et al., 1996, 1997; Bussey, Everitt, \& Robbins, 1997; Gabriel, 1993; Gabriel, Kubota, Sparenborg, Straube, \& Vogt, 1991; Parkinson, Cardinal, \& Everitt, 2000; Parkinson, Willoughby, et al., 2000).

\section{Nature of the Autoshaping Deficit}

Previous studies have consistently found that ACC-lesioned rats approach the CS - more than control rats (Bussey, Everitt, \& Robbins, 1997; Parkinson, Willoughby, et al., 2000), whereas the performance deficit in the present experiment was due to a reduction in CS + approach (the transient postoperative increase in CSapproach was not significantly greater than that observed in shamoperated controls). It may be that a failure to discriminate between the two stimuli may naturally manifest itself as an alteration in either decreased $\mathrm{CS}+$ or increased $\mathrm{CS}-$ responding. In principle, this might be influenced by the level of general activity of the subjects in the autoshaping apparatus; however, it is important to note that hyperactive animals can show reduced CS approach (Parkinson et al., 1999; Parkinson, Willoughby, et al., 2000); thus, differences in general activity levels are dissociable from autoshaping, and other factors may have contributed to the present specific deficit in $\mathrm{CS}+$ responding (discussed below). Furthermore, though lesioned subjects were slower to approach the stimuli (as observed by Bussey, Everitt, \& Robbins, 1997), slow responding is not a plausible explanation of the residual impairment in discrimination exhibited by ACC-lesioned rats, as their discrimination was also impaired when their approaches to the $\mathrm{CS}+$ were considered relative to the total number of trials on which they approached a stimulus (i.e., examining ratio scores during performance and during the probe test). Regardless of the specific form of the deficit, impairments in $\mathrm{CS}+/ \mathrm{CS}$ - discrimination have been a consistent feature of autoshaping in ACC-lesioned rats, whether assessed by acquisition or performance testing, or by probe tests (Bussey, Everitt, \& Robbins, 1997; Parkinson, Willoughby, et al., 2000; present data).

In the present study, a very high level of CS + approach was attained preoperatively, compared with that of previous studies (Bussey, Everitt, \& Robbins, 1997; Parkinson, Willoughby, et al., 2000), due to the use of a selection criterion. Another interpretation supported by the present data, therefore, is that the ACC contributes to CS + approach, especially in those subjects who discriminate very well; this effect may usually be masked by variability in normal subjects.

\section{Learning Versus Performance}

The finding that posttraining ACC lesions impair autoshaping performance strongly suggests that the ACC does not merely control learning in other systems, but is involved in storing or retrieving stimulus-reward associations (a mnemonic role) or in the mechanism of behavioral expression.

Although the above claim holds whether the impairment was permanent or transient, the issue is complicated by three observations. First, some functional recovery occurred. Second, the lesions impaired autoshaping performance less than ACC lesions made before training (Bussey, Everitt, \& Robbins, 1997; Parkinson, Willoughby, et al., 2000). Third, some discrimination may eventually be attained by ACC-lesioned rats even if the lesions are made before the acquisition of autoshaping (Parkinson, Willoughby, et al., 2000, p. 49), though such subjects never attained the performance of sham-lesioned subjects. Thus, it is possible that the contribution of the ACC to performance diminishes with time.

There is evidence that the ACC has a time-limited role in other tasks, that is, the ACC is particularly important early in learning. Gabriel et al. (1991) have studied a two-way active avoidance task, in which rabbits must run in response to a $\mathrm{CS}+$ (but not a $\mathrm{CS}-$ ) to avoid shock. They found that ACC lesions impair acquisition of this task, but avoidance behavior is eventually acquired. Furthermore, when ACC lesions are made after acquisition, the lesions do not impair performance as much as they do when made before training (Freeman, Cuppernel, Flannery, \& Gabriel, 1996; Gabriel, 1993; Gabriel, Foster, Orona, Saltwick, \& Stanton, 1980, p. 162; Hart, Poremba, \& Gabriel, 1997). Gabriel et al. suggest that the ACC (together with the mediodorsal thalamus) rapidly acquires the CS+/CS - discrimination, then "teaches" other structures, including the anteroventral thalamus and posterior cingulate cortex, releasing the ACC for further learning; Gabriel et al. have suggested this as an analogue of behavioral automatization (Freeman et al., 1996; Gabriel et al., 1980, pp. 143-163 / 220). This idea also accords with views of the primate ACC as a specialized "error detector" (Bush, Luu, \& Posner, 2000; Coles, Scheffers, \& Holroyd, 1998; Gehring, Goss, Coles, Meyer, \& Donchin, 1993; Schultz \& Dickinson, 2000); a structure responsible for error detection and correction might become less important as the task is automatized. Indeed, the contribution of the human ACC to performance of a variety of tasks appears to diminish with time and practice (Petersen, van Mier, Fiez, \& Raichle, 1998; Raichle et al., 1994).

\section{Experiment 3: Lesions of the $\mathrm{CeA}$}

\section{Method}

Thirty-two male hooded Lister rats were maintained at $90 \%$ of their free-feeding body weight and trained for 100 trials as described in Experiment 1 . Subjects that failed to approach the CS+ on at least $70 \%$ of the last 30 trials were given a further 50 remedial trials; if they failed to meet this criterion on the last 30 remedial trials, they were then excluded from the experiment. The successful subjects were given free access to food and randomly assigned to groups that received lesions of the $\mathrm{CeA}$ or sham lesions; at the time of operation, they weighed 282-379 g. Surgical methods were as for Experiment 1, except that $0.06 \mathrm{M}$ ibotenic acid was used as the toxin and injected through a 1- $\mu$ l syringe (SGE Ltd). Lesion coordinates were AP -2.2 and $-2.7, \mathrm{ML} \pm 4.0, \mathrm{DV}-7.8$ from the skull surface $(0.2 \mu \mathrm{l}$ per site, infused over $2 \mathrm{~min}$, with $10 \mathrm{~min}$ diffusion time allowed before removal of the syringe). After recovery, rats were returned to the food-deprivation regimen. Their performance on the same autoshaping task was tested for a further 50 trials; they then received a probe test (as described in Experiment 2). 


\section{Results}

Eight subjects failed to reach the acquisition criterion. Of those that reached the criterion, 16 subjects received CeA lesions and 8 subjects received sham lesions. Rats with unilateral lesions (3), no lesion (1), incomplete bilateral lesions (2), or extensive lesions including the basal and medial amygdala (2) were excluded from analysis, leaving 8 subjects with total or very large lesions of the CeA. Lesions extended from approximately $-1.6 \mathrm{~mm}$ to $-0.2 \mathrm{~mm}$ from bregma and encompassed much of the medial, lateral, and capsular aspects of the CeA. Lesion schematics are shown in Figure 1; photomicrographs of lesions using these parameters have been presented previously (Killcross, Robbins, \& Everitt, 1997; Parkinson, Robbins, \& Everitt, 2000). Exploratory data analysis revealed that 1 subject in the sham group was an outlier (complete absence of approach behavior on two consecutive sessions, with data points consistently $>2 S D$ from the group mean); this subject was excluded. Thus, the final group sizes were 8 (CeA-lesioned) and 7 (sham).

\section{Preoperative Acquisition}

Both groups reached the same asymptote of performance (see Figures 4A-4C). The difference scores for the last three blocks of preoperative training (10 trials per block) were analyzed using the model Group $_{2} \times\left(\right.$ Block $\left._{3} \times S\right)$; no terms were significant $(F \mathrm{~s}<1)$.

\section{Postoperative Performance}

There were no differences between the sham and CeA-lesioned groups in postoperative performance (see Figures 4A-4D). Difference scores were analyzed with the model Group $_{2} \times\left(\right.$ Block $_{5} \times$ $S)$; in this analysis, no term was significant $(F \mathrm{~s}<1)$. A similar analysis of ratio scores showed no effect of any term $(F \mathrm{~s}<1, n s)$; the same was true of analyses of $\mathrm{CS}+$ approaches: group, $F(1$, $13)=2.30, n s$ (other $\left.F_{\mathrm{S}}<1.36, n s\right)$, and $\mathrm{CS}-$ approaches: Group $\times$ Block, $F(4,52)=1.56, n s($ other $F \mathrm{~s}<1, n s)$. Analysis of approach latencies, using the model Group $_{2} \times\left(\right.$ Stimulus $\left._{2} \times S\right)$, showed that all subjects approached the $\mathrm{CS}+$ faster than the $\mathrm{CS}-$ : main effect of stimulus, $F(1,12)=16.1, p=.002$, but there were no group differences: group, $F(1,12)=2.14$, $n s$; Group $\times$ Stimulus, $F<1$, ns. Primary consummatory behavior was unaffected by the lesion: at no point did any rat fail to consume all the pellets.

\section{Probe Test}

The CeA-lesioned rats performed normally on the probe test (see Figure 4E). A discrimination ratio was calculated as the number of trials on which the $\mathrm{CS}+$ was approached divided by the number of trials on which either stimulus was approached. Analysis of this measure by one-way ANOVA revealed no difference between the groups $(F<1, n s)$.

\section{Summary}

CeA lesions had no effect on the performance of a previously learned autoshaped response.

\section{Discussion}

The complete absence of deficits in autoshaping performance contrasts with the profound deficit found after identical CeA lesions made before training (Parkinson, Robbins, \& Everitt, 2000). The present result demonstrates that the CeA is not required for the behavioral expression of autoshaping, and by inference it is selectively involved in the learning of the task. This is an unusual and important finding.

The present results and those of Parkinson, Robbins, and Everitt (2000) do not specify the precise function that the CeA contributes to learning. However, the simplicity of the autoshaping task used allows some explanations to be ruled out. As CeA lesions did not prevent subjects from consuming the reinforcer, or from perceiving and discriminating the stimuli in the present study, it is highly unlikely that the acquisition deficit (Parkinson, Robbins, \& Everitt, 2000) was due to the rats not experiencing CS-US pairings. Therefore, in the study of Parkinson, Robbins, and Everitt (2000), CeA lesions appear to have prevented this experience from being translated into an associative representation that subsequently controlled behavior.

One explanation is that the $\mathrm{CeA}$ is involved in the control of attentional processes (Everitt, Cardinal, et al., 2000; Gallagher \& Holland, 1994; Holland \& Gallagher, 1999). The CeA projects to a wide range of diffuse projection systems in the brainstem and basal forebrain, including the noradrenergic locus coeruleus, the dopaminergic substantia nigra pars compacta and ventral tegmental area (VTA), the serotonergic raphé nuclei, and the cholinergic nucleus basalis magnocellularis (NBM; Amaral, Price, Pitkänen, \& Carmichael, 1992; Davis, 1992; Gallagher \& Holland, 1994; Pitkänen, 2000; Price, Russchen, \& Amaral, 1987). Through its projection to the NBM, the CeA is capable of increasing the associability of CSs (Han, Holland, \& Gallagher, 1999), most likely in neocortical sites (Holland, 1997; Weinberger, 1995, 1998). This is a mechanism through which the CeA could promote the formation of CS-US associations, and one which would not contribute to performance once the association had been formed.

The CeA also influences striatal DA levels. Through its projection to the nigrostriatal DA system innervating the dorsolateral caudate-putamen, the $\mathrm{CeA}$ influences orienting responses (Han et al., 1997). Additionally, through its projection to the VTA (Fudge \& Haber, 2000; Hopkins \& Holstege, 1978; Krettek \& Price, 1978; Price \& Amaral, 1981), the CeA may influence Acb DA levels (Everitt, Cardinal, et al., 2000; Everitt et al., 1999; Hall et al., 1999). For example, dopaminergic lesions of the CeA and infusions of DA receptor antagonists into the amygdala both affect levels of extracellular DA in the Acb (Louilot, Simon, Taghzouti, \& Le Moal, 1985; Simon et al., 1988). In experiments similar to those reported here, we have recently found that 6-hydroxydopamine-induced DA depletion of the Acb produces a profound deficit in autoshaping acquisition, and a significant, stable, but small deficit in performance (Parkinson et al., in press). Direct infusion of the mixed $\mathrm{DA} \mathrm{D}_{1} / \mathrm{D}_{2}$ receptor antagonist $\alpha$-flupenthixol into the AcbC also blocks the acquisition of autoshaping completely and impairs autoshaping performance significantly, though to a lesser degree (Di Ciano et al., 2001). These results suggest that Acb DA has a twin role, not only in maintain- 
A

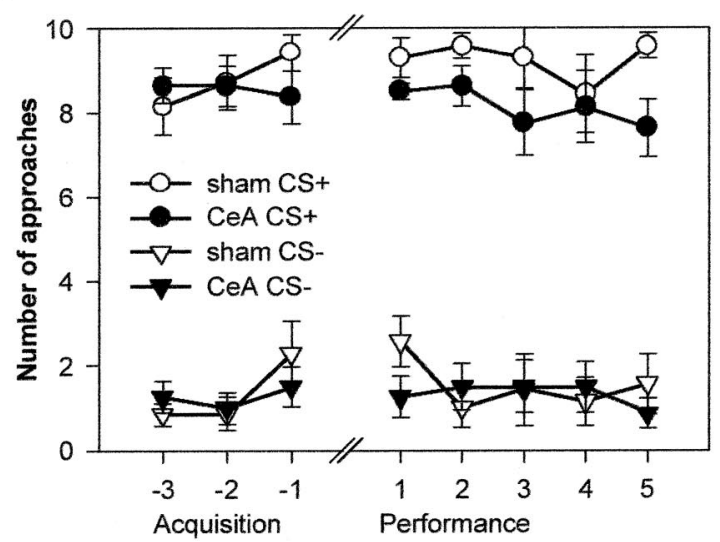

Trial block

C

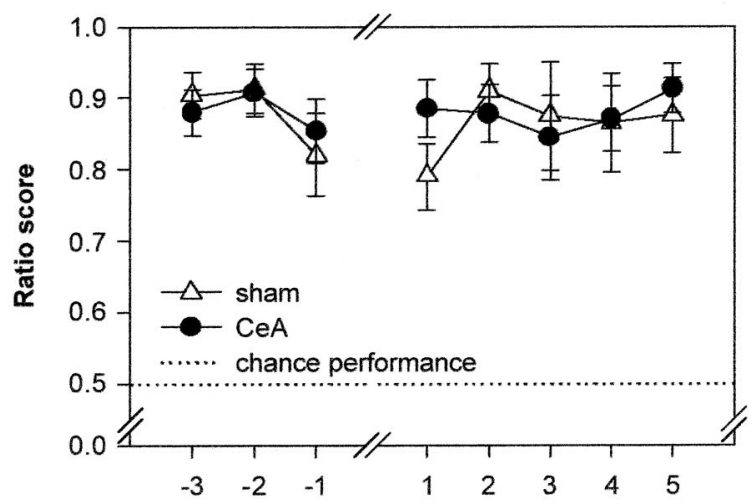

Trial block

$\mathbf{E}$

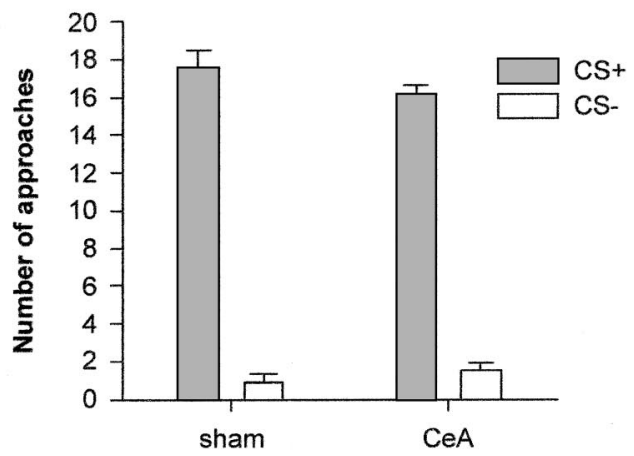

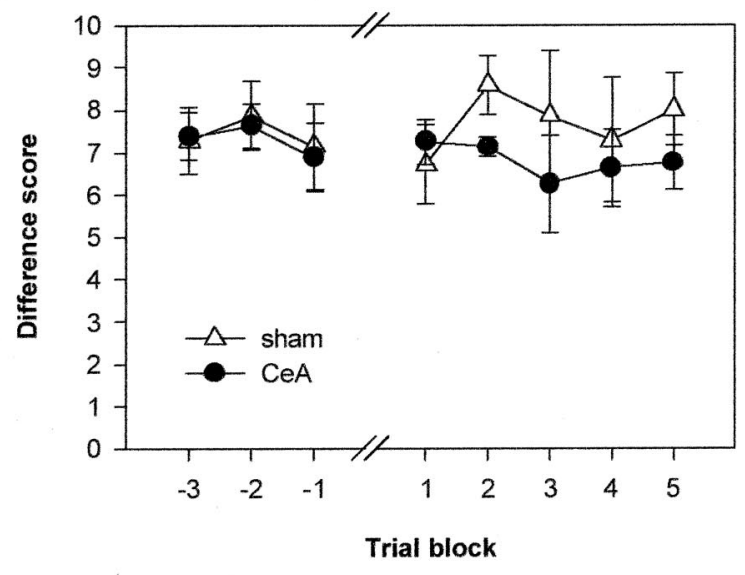

$\mathbf{D}$

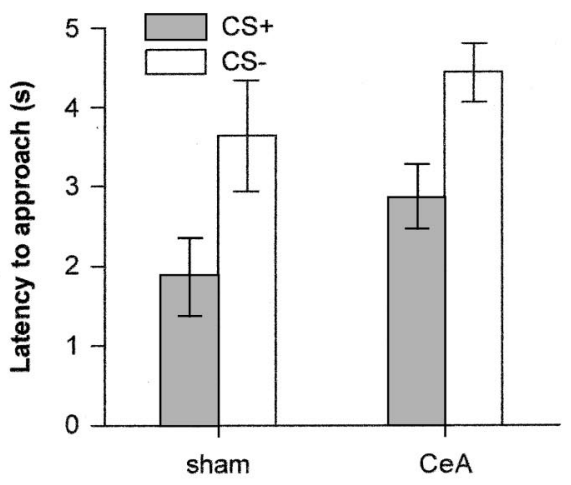

Figure 4. Posttraining lesions of the central nucleus of the amygdala (CeA) had no effect on autoshaping performance. The final three sessions of preoperative acquisition training are shown, together with postoperative performance. A: Approach to paired conditioned stimulus $(\mathrm{CS}+)$ and the unpaired stimulus $(\mathrm{CS}-)$. B: Difference scores. C: Discrimination ratio scores. D: Latencies to approach each stimulus. E: Autoshaping probe test. (Note that approaches to the CS + and CS - are mutually exclusive on any given trial.) Data are means ( \pm SEM).

ing performance, but also specifically in learning. Thus, a further, highly speculative interpretation of the effects of CeA lesions is that they prevent the phasic changes in Acb DA that have been suggested to contribute to striatal learning (Kiyatkin, 1995; Par- kinson et al., in press; Schultz, Dayan, \& Montague, 1997; Schultz \& Dickinson, 2000), while not eliminating the tonic, background level of Acb DA necessary for normal performance of autoshaping (Parkinson et al., 2000). 


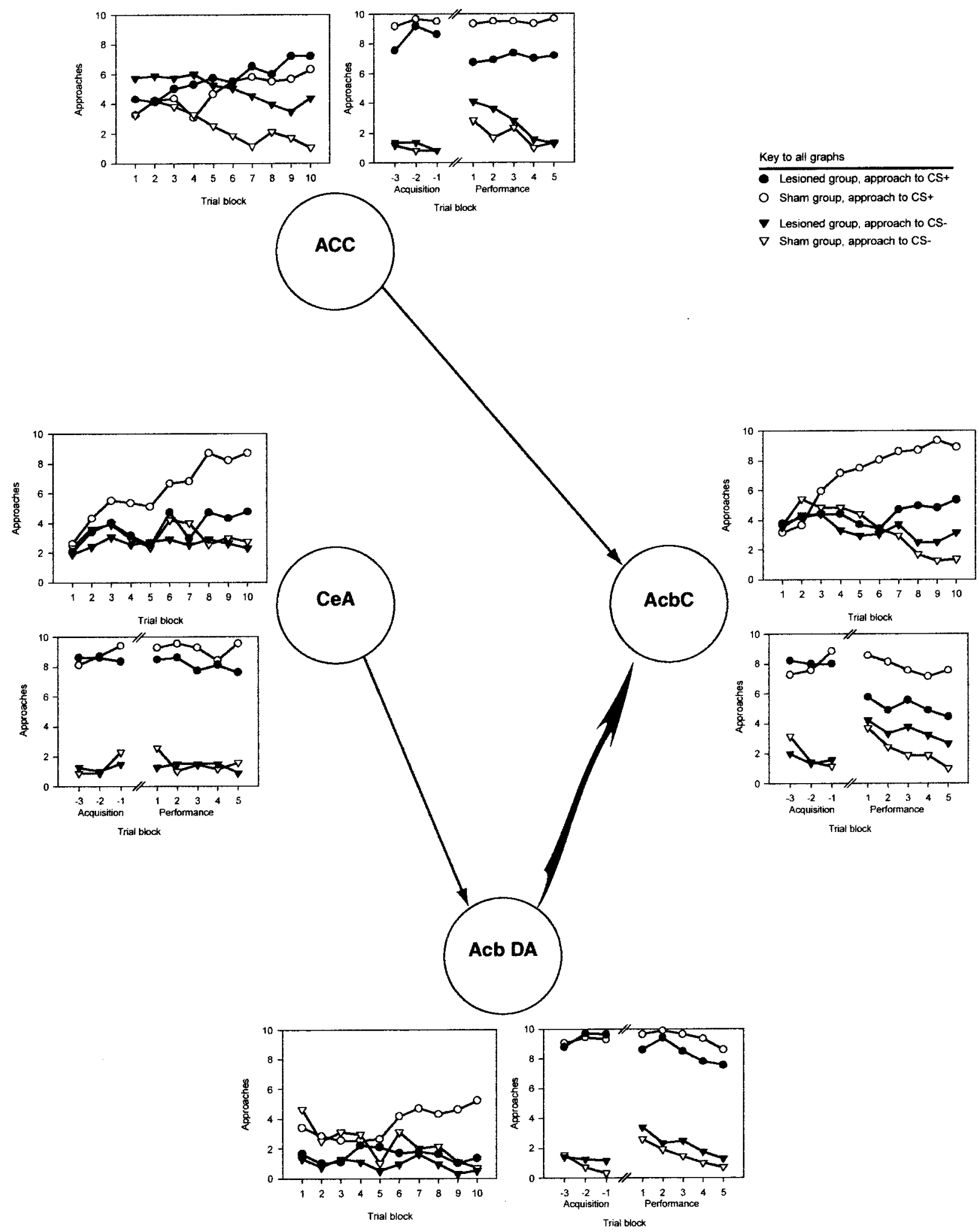




\section{General Discussion}

The present study investigated a network of structures known to be required for the acquisition of autoshaping (illustrated in Figure 5). Whereas the AcbC and ACC also contributed to performance of an autoshaped response after training, the CeA was not required, implying that it contributes specifically to the learning of CS-US associations in other sites.

Although lesions of the AcbC and ACC both produced impairments in performance, these impairments were qualitatively different. Lesions of the AcbC completely abolished the expression of autoshaping, consistent with theories of the Acb as a site through which Pavlovian CSs influence locomotor and instrumental behavior (Cardinal, Parkinson, Hall, \& Everitt, 2002; Parkinson, Cardinal, \& Everitt, 2000). The AcbC may be seen as a final common output structure for autoshaping.

In contrast, lesions of the ACC did not completely abolish autoshaped behavior, and some recovery occurred in ACClesioned rats. Thus, although the projection from the ACC to the $\mathrm{AcbC}$ is required for the development of autoshaped behavior (Parkinson, Willoughby, et al., 2000), the ACC is not simply an output structure. As discussed above, it is possible that the ACC's role is transient; it is not presently known whether autoshaping survives ACC lesions after overtraining far beyond the acquisition of asymptotic levels of conditioned approach. However, when the ACC does make a contribution to autoshaping, what is its role? The ACC does not appear to be required for simple perceptual discrimination among stimuli, but it does appear to be required in tasks where multiple stimuli must be discriminated according to their (differential) association with reinforcement (Cardinal, Parkinson, Djafari Marbini, et al., 2002; Parkinson, Cardinal, \& Everitt, 2000). Thus, it has been suggested that the ACC "disambiguates" CSs on this basis for the limbic corticostriatal circuit of which it is part-specifically, for the AcbC (Cardinal, Parkinson, Hall, \& Everitt, 2002; Parkinson, Cardinal, \& Everitt, 2000). The present results are compatible with this hypothesis.

Lesions of the CeA had no impact on performance of the autoshaped response, yet such lesions profoundly impair the acquisition of autoshaping (Parkinson, Robbins, \& Everitt, 2000). The neural and psychological mechanism through which the CeA contributes specifically to the learning of the autoshaped response is not yet clear. The CeA is known to control neural circuits responsible for the determination of the associability of stimuli (Han et al., 1999) and to regulate the conditioned orienting response, a mechanism for directing sensory systems at significant stimuli (Han, McMahan, Holland, \& Gallagher, 1997). Additionally, as discussed above, the CeA projects to the VTA and regulates the dopaminergic innervation of the Acb (Louilot et al., 1985; Simon et al., 1988). Acb DA appears to play a vital role in learning the autoshaped approach response, over and above its role in performance (Di Ciano et al., 2001; Parkinson et al., in press). We speculate that the $\mathrm{CeA}$ may control a dopaminergic reinforcement signal for striatal stimulus-response learning (more specifically, a phasic DA signal; Parkinson et al., in press). In the case of autoshaping, the CeA may supervise the strengthening of associations between environmental stimuli and motivational responses (measured as locomotor approach) in the AcbC; these associations have been suggested to represent "motivational habits" (Cardinal, Parkinson, Hall, \& Everitt, 2002; Parkinson, Cardinal, \& Everitt, 2000).

These results provide further insight into the complex neural mechanisms through which an apparently simple, yet biologically important, behavior (Hearst \& Jenkins, 1974; Tomie et al., 1989) develops and is expressed. Because autoshaping may also contribute to addictive behavior (Altman et al., 1996; Robbins \& Everitt, 1999; Tiffany, 1990; Tomie, 1996), an understanding of its neural basis is important from a therapeutic viewpoint: Plasticity within and governed by the structures investigated here may contribute to involuntary approach to stimuli that are predictive of drug rewards.

\section{References}

Altman, J., Everitt, B. J., Glautier, S., Markou, A., Nutt, D., Oretti, R., et al. (1996). The biological, social and clinical bases of drug addiction: Commentary and debate. Psychopharmacology (Berlin), 125, 285-345.

Amaral, D. G., Price, J. L., Pitkänen, A., \& Carmichael, S. T. (1992). Anatomical organization of the primate amygdaloid complex. In J. P. Aggleton (Ed.), The amygdala: Neurobiological aspects of emotion, memory, and mental dysfunction (pp. 1-66). New York: Wiley-Liss.

Balleine, B. (1994). Asymmetrical interactions between thirst and hunger in Pavlovian-instrumental transfer. Quarterly Journal of Experimental Psychology: Comparative and Physiological Psychology, 47(B), B211B231.

Balleine, B., \& Killcross, S. (1994). Effects of ibotenic acid lesions of the

Figure 5 (opposite). Schematic of part of the neural circuitry involved in autoshaping in rats, with data illustrating the effect of pre- and posttraining lesions of each structure. The first of the two graphs in each pair illustrates the effects of lesions on the acquisition of autoshaping, across 10 blocks of 10 trials. The second graph illustrates the effects of lesions on the behavior of well-trained rats ( 3 prelesion trial blocks and 5 postlesion trial blocks; breaks in the horizontal axis indicate the time of surgery). The anterior cingulate cortex (ACC) is required for the acquisition of autoshaping (as is its connection to the nucleus accumbens core $[\mathrm{AcbC}]$ ), and it plays some role in performance, although a degree of discriminated autoshaping survives ACC lesions. The $\mathrm{AcbC}$ is required for both acquisition and performance, suggesting it is part of the "final common output" for the expression of autoshaping. The central nucleus of the amygdala (CeA) is required for acquisition, but not for expression, of learned associations, implying that it contributes specifically to the learning of the associations underlying autoshaping. Similarly, dopamine (DA)-depleting lesions of the AcbC completely abolish the acquisition of autoshaping, and though such lesions have a statistically significant effect on performance, that effect was minor, suggesting that the DA innervation of the AcbC plays a role in learning, possibly under the control of the CeA. Data are means. Performance data for ACC, CeA, and AcbC lesions are from the present study; Acb DA-depleting lesion data are from Parkinson et al. (in press); CeA acquisition data are from Parkinson, Robbins, and Everitt (2000); and AcbC and ACC acquisition data are from Parkinson, Willoughby, et al. (2000). All these experiments were conducted in the same laboratory with the same apparatus. 
nucleus accumbens on instrumental action. Behavioural Brain Research, 65, 181-193.

Balleine, B. W., \& Dickinson, A. (1998). Goal-directed instrumental action: Contingency and incentive learning and their cortical substrates. Neuropharmacology, 37, 407-419.

Brog, J. S., Salyapongse, A., Deutch, A. Y., \& Zahm, D. S. (1993). The patterns of afferent innervation of the core and shell in the "accumbens" part of the rat ventral striatum: Immunohistochemical detection of retrogradely transported fluoro-gold. Journal of Comparative Neurology, 338, 255-278.

Brown, P. L., \& Jenkins, H. M. (1968). Auto-shaping of the pigeon's keypeck. Journal of the Experimental Analysis of Behavior, 11, 1-8.

Browne, M. P. (1976). The role of primary reinforcement and overt movements in auto-shaping in the pigeon. Animal Learning \& Behavior, 4, 287-292.

Buchanan, S. L., \& Powell, D. A. (1982). Cingulate cortex: Its role in Pavlovian conditioning. Journal of Comparative and Physiological Psychology, 96, 755-774.

Bush, G., Luu, P., \& Posner, M. I. (2000). Cognitive and emotional influences in anterior cingulate cortex. Trends in Cognitive Sciences, 4 , 215-222.

Bussey, T. J., Everitt, B. J., \& Robbins, T. W. (1997). Dissociable effects of cingulate and medial frontal cortex lesions on stimulus-reward learning using a novel Pavlovian autoshaping procedure for the rat: Implications for the neurobiology of emotion. Behavioral Neuroscience, 111, 908-919.

Bussey, T. J., Muir, J. L., Everitt, B. J., \& Robbins, T. W. (1996). Dissociable effects of anterior and posterior cingulate cortex lesions on the acquisition of a conditional visual discrimination: Facilitation of early learning vs. impairment of late learning. Behavioural Brain Research, 82, 45-56.

Bussey, T. J., Muir, J. L., Everitt, B. J., \& Robbins, T. W. (1997). Triple dissociation of anterior cingulate, posterior cingulate, and medial frontal cortices on visual discrimination tasks using a touchscreen testing procedure for the rat. Behavioral Neuroscience, 111, 920-936.

Cardinal, R. N., Lachenal, G., Parkinson, J. A., Robbins, T. W., \& Everitt, B. J. (2000). Effects of anterior cingulate cortex lesions on responding for conditioned reinforcement, discrete fear conditioning, autoshaping performance and Pavlovian-instrumental transfer. European Journal of Neuroscience, 12(Suppl. 11), 88.

Cardinal, R. N., Parkinson, J. A., Djafari Marbini, H., Toner, A. J., Bussey, T. J., Robbins, T. W., \& Everitt, B. J. (2002). Role of the anterior cingulate cortex in the control over behaviour by Pavlovian conditioned stimuli in rats. Manuscript in preparation.

Cardinal, R. N., Parkinson, J. A., Hall, J., \& Everitt, B. J. (2002). Emotion and motivation: The role of the amygdala, ventral striatum, and prefrontal cortex. Neuroscience and Biobehavioral Reviews, 26, 321-352.

Coles, M. G. H., Scheffers, M. K., \& Holroyd, C. (1998). Berger's dream? The error-related negativity and modern cognitive psychophysiology. In H. Witte, U. Zwiener, B. Schack, \& A. Döring (Eds.), Quantitative and topological EEG and EMG analysis (pp. 96-102). Jena-Erlangen, Germany: Druckhaus Mayer Verlag.

Davis, M. (1992). The role of the amygdala in conditioned fear. In J. P. Aggleton (Ed.), The amygdala: Neurobiological aspects of emotion, memory, and mental dysfunction (pp. 255-306). New York: Wiley-Liss.

Di Ciano, P., Cardinal, R. N., Cowell, R. A., Little, S. J., \& Everitt, B. J. (2001). Differential involvement of NMDA, AMPA/kainate, and dopamine receptors in the nucleus accumbens core in the acquisition and performance of Pavlovian approach behavior. Journal of Neuroscience, 21, 9471-9477.

Dickinson, A. (1994). Instrumental conditioning. In N. J. Mackintosh (Ed.), Animal learning and cognition (pp. 45-79). San Diego, CA: Academic Press.

Dickinson, A., \& Dawson, G. R. (1987). Pavlovian processes in the motivational control of instrumental performance. Quarterly Journal of
Experimental Psychology: Comparative and Physiological Psychology, 39(B), B201-B213.

Dickinson, A., Watt, A., \& Griffiths, W. J. H. (1992). Free-operant acquisition with delayed reinforcement. Quarterly Journal of Experimental Psychology: Comparative and Physiological Psychology, 45(B), B241-B258.

Everitt, B. J., Cardinal, R. N., Hall, J., Parkinson, J. A., \& Robbins, T. W. (2000). Differential involvement of amygdala subsystems in appetitive conditioning and drug addiction. In J. P. Aggleton (Ed.), The amygdala: A functional analysis (2nd ed., pp. 353-390). New York: Oxford University Press.

Everitt, B. J., Parkinson, J. A., Lachenal, G., Halkerston, K. M., Rudarakanchana, N., Cardinal, R. N., et al. (2000). Effects of limbic corticostriatal lesions on autoshaping performance in rats. Society for Neuroscience Abstracts, 26, 979.

Everitt, B. J., Parkinson, J. A., Olmstead, M. C., Arroyo, M., Robledo, P., \& Robbins, T. W. (1999). Associative processes in addiction and reward: The role of amygdala-ventral striatal subsystems. In J. F. McGinty (Ed.), Annals of the New York Academy of Sciences: Vol. 877. Advancing from the ventral striatum to the extended amygdala: Implications for neuropsychiatry and drug abuse (pp. 412-438). New York: New York Academy of Sciences.

Freeman, J. H., Jr., Cuppernell, C., Flannery, K., \& Gabriel, M. (1996). Limbic thalamic, cingulate cortical and hippocampal neuronal correlates of discriminative approach learning in rabbits. Behavioural Brain Research, 80, 123-136.

Fudge, J. L., \& Haber, S. N. (2000). The central nucleus of the amygdala projection to dopamine subpopulations in primates. Neuroscience, 97, 479-494.

Gabriel, M. (1993). Discriminative avoidance learning: A model system. In B. A. Vogt \& M. Gabriel (Eds.), Neurobiology of cingulate cortex and limbic thalamus: A comprehensive handbook (pp. 478-523). Boston: Birkhauser.

Gabriel, M., Foster, K., Orona, E., Saltwick, S., \& Stanton, M. (1980). Neuronal activity of cingulate cortex, anteroventral thalamus, and hippocampal formation in discriminative conditioning: Encoding and extraction of the significance of conditional stimuli. In J. M. Sprague \& A. N. Epstein (Eds.), Progress in psychobiology and physiological psychology (Vol. 9, pp. 125-231). New York: Academic Press.

Gabriel, M., Kubota, Y., Sparenborg, S., Straube, K., \& Vogt, B. A. (1991). Effects of cingulate cortical lesions on avoidance learning and traininginduced unit activity in rabbits. Experimental Brain Research, 86, 585-600.

Gallagher, M., \& Holland, P. C. (1994). The amygdala complex: Multiple roles in associative learning and attention. Proceedings of the National Academy of Sciences, USA, 91, 11771-11776.

Gehring, W. J., Goss, B., Coles, M. G. H., Meyer, D. E., \& Donchin, E. (1993). A neural system for error detection and compensation. Psychological Science, 4, 385-390.

Hall, J., Parkinson, J. A., Connor, T. M., Dickinson, A., \& Everitt, B. J. (2001). Involvement of the central nucleus of the amygdala and nucleus accumbens core in mediating Pavlovian influences on instrumental behaviour. European Journal of Neuroscience, 13(10), 1984-1992.

Hall, J., Parkinson, J. A., Connor, T. M. F., Di Ciano, P., Dickinson, A., \& Everitt, B. J. (1999). The role of amygdala-ventral striatal sub-systems in Pavlovian to instrumental transfer. Society for Neuroscience Abstracts, 25, 90.

Han, J. S., Holland, P. C., \& Gallagher, M. (1999). Disconnection of the amygdala central nucleus and substantia innominata/nucleus basalis disrupts increments in conditioned stimulus processing in rats. Behavioral Neuroscience, 113, 143-151.

Han, J. S., McMahan, R. W., Holland, P., \& Gallagher, M. (1997). The role of an amygdalo-nigrostriatal pathway in associative learning. Journal of Neuroscience, 17, 3913-3919.

Hart, M., Poremba, A., \& Gabriel, M. (1997). The nomadic engram: Overtraining eliminates the impairment of discriminative avoidance 
behavior produced by limbic thalamic lesions. Behavioural Brain Research, 82, 169-177.

Hearst, E., \& Jenkins, H. M. (1974). Sign tracking: The stimulus-reinforcer relation and directed action. Austin, TX: Psychonomic Society.

Holland, P. C. (1997). Brain mechanisms for changes in processing of conditioned stimuli in Pavlovian conditioning: Implications for behavior theory. Animal Learning \& Behavior, 25, 373-399.

Holland, P. C., \& Gallagher, M. (1999). Amygdala circuitry in attentional and representational processes. Trends in Cognitive Sciences, 3, 65-73.

Hopkins, D. A., \& Holstege, G. (1978). Amygdaloid projections to the mesencephalon, pons and medulla oblongata in the cat. Experimental Brain Research, 32, 529-547.

Howell, D. C. (1997). Statistical methods for psychology (4th ed.). Belmont, CA: Wadsworth.

Huynh, H., \& Feldt, L. S. (1970). Conditions under which mean square ratios in repeated measures designs have exact $F$-distributions. Journal of the American Statistical Association, 65, 1582-1589.

Jenkins, H. M., \& Moore, B. R. (1973). The form of the auto-shaped response with food or water reinforcers. Journal of the Experimental Analysis of Behavior, 20, 163-181.

Kelley, A. E., SmithRoe, S. L., \& Holahan, M. R. (1997). Responsereinforcement learning is dependent on $N$-methyl-D-aspartate receptor activation in the nucleus accumbens core. Proceedings of the National Academy of Sciences, USA, 94, 12174-12179.

Keppel, G. (1982). Design and analysis: A researcher's handbook (2nd ed.). London: Prentice-Hall.

Killcross, S., Robbins, T. W., \& Everitt, B. J. (1997, July 24). Different types of fear-conditioned behaviour mediated by separate nuclei within amygdala. Nature, 388, 377-380.

Kiyatkin, E. A. (1995). Functional significance of mesolimbic dopamine. Neuroscience and Biobehavioral Reviews, 19, 573-598.

Krettek, J. E., \& Price, J. L. (1978). A description of the amygdaloid complex in the rat and cat with observations on intra-amygdaloid axonal connections. Journal of Comparative Neurology, 178, 255-280.

Louilot, A., Simon, H., Taghzouti, K., \& Le Moal, M. (1985). Modulation of dopaminergic activity in the nucleus accumbens following facilitation or blockade of the dopaminergic transmission in the amygdala: A study by in vivo differential pulse voltammetry. Brain Research, 346, 141-145.

Mackintosh, N. J. (1974). The psychology of animal learning. London: Academic Press.

Mogenson, G. J., Jones, D. L., \& Yim, C. Y. (1980). From motivation to action: Functional interface between the limbic system and the motor system. Progress in Neurobiology, 14, 69-97.

Moore, B. R. (1973). The role of directed Pavlovian reactions in simple instrumental learning in the pigeon. In R. A. Hinde \& J. StevensonHinde (Eds.), Constraints on learning: Limitations and predispositions (pp. 159-188). New York: Academic Press.

Parkinson, J. A., Cardinal, R. N., \& Everitt, B. J. (2000). Limbic corticalventral striatal systems underlying appetitive conditioning. Progress in Brain Research, 126, 263-285.

Parkinson, J. A., Dalley, J. W., Cardinal, R. N., Bamford, A., Fehnert, B., Lachenal, G., et al. (in press). Nucleus accumbens dopamine depletion impairs both acquisition and performance of appetitive Pavlovian approach behaviour: Implications for mesoaccumbens dopamine function. Behavioural Brain Research.

Parkinson, J. A., Olmstead, M. C., Burns, L. H., Robbins, T. W., \& Everitt, B. J. (1999). Dissociation in effects of lesions of the nucleus accumbens core and shell on appetitive Pavlovian approach behavior and the potentiation of conditioned reinforcement and locomotor activity by $d$-amphetamine. Journal of Neuroscience, 19, 2401-2411.

Parkinson, J. A., Robbins, T. W., \& Everitt, B. J. (1996). Lesions of the nucleus accumbens core, but not basolateral amygdala or subiculum, disrupt stimulus-reward learning in a novel autoshaping procedure. Society for Neuroscience Abstracts, 22, 1118.
Parkinson, J. A., Robbins, T. W., \& Everitt, B. J. (2000). Dissociable roles of the central and basolateral amygdala in appetitive emotional learning. European Journal of Neuroscience, 12, 405-413.

Parkinson, J. A., Willoughby, P. J., Robbins, T. W., \& Everitt, B. J. (2000). Disconnection of the anterior cingulate cortex and nucleus accumbens core impairs Pavlovian approach behavior: Further evidence for limbic corticalventral striatopallidal systems. Behavioral Neuroscience, 114, 42-63.

Paxinos, G., \& Watson, C. (1996). The rat brain in stereotaxic coordinates (3rd ed.). San Diego, CA: Academic Press.

Paxinos, G., \& Watson, C. (1998). The rat brain in stereotaxic coordinates (4th ed.). San Diego, CA: Academic Press.

Petersen, S. E., van Mier, H., Fiez, J. A., \& Raichle, M. E. (1998). The effects of practice on the functional anatomy of task performance. Proceedings of the National Academy of Sciences, USA, 95, 853-860.

Pitkänen, A. (2000). Connectivity of the rat amygdaloid complex. In J. P. Aggleton (Ed.), The amygdala: A functional analysis (2nd ed., pp. 31-115). New York: Oxford University Press.

Price, J. L., \& Amaral, D. G. (1981). An autoradiographic study of the projections of the central nucleus of the monkey amygdala. Journal of Neuroscience, 1, 1242-1259.

Price, J. L., Russchen, F. T., \& Amaral, D. G. (1987). The limbic region. II: The amygdaloid complex. In A. Björklund, T. Hökfelt, \& L. W. Swanson (Eds.), Handbook of chemical neuroanatomy, Volume 5: Integrated systems of the CNS, Part 1 (pp. 279-388). Amsterdam: Elsevier.

Raichle, M. E., Fiez, J. A., Videen, T. O., MacLeod, A. M., Pardo, J. V., Fox, P. T., \& Petersen, S. E. (1994). Practice-related changes in human brain functional anatomy during nonmotor learning. Cerebral Cortex, 4, 8-26.

Robbins, T. W., \& Everitt, B. J. (1999, April 15). Drug addiction: Bad habits add up. Nature, 398, 567-570.

Schultz, W., Dayan, P., \& Montague, P. R. (1997, March 14). A neural substrate of prediction and reward. Science, 275, 1593-1599.

Schultz, W., \& Dickinson, A. (2000). Neuronal coding of prediction errors. Annual Review of Neuroscience, 23, 473-500.

Simon, H., Taghzouti, K., Gozlan, H., Studler, J. M., Louilot, A., Herve, D., et al. (1988). Lesion of dopaminergic terminals in the amygdala produces enhanced locomotor response to $d$-amphetamine and opposite changes in dopaminergic activity in prefrontal cortex and nucleus accumbens. Brain Research, 447, 335-340.

Tiffany, S. T. (1990). A cognitive model of drug urges and drug-use behavior: Role of automatic and nonautomatic processes. Psychological Review, 97, 147-168.

Tomie, A. (1996). Locating reward cue at response manipulandum (CAM) induces symptoms of drug abuse. Neuroscience and Biobehavioral Review, 20, 505-535.

Tomie, A., Brooks, W., \& Zito, B. (1989). Sign-tracking: The search for reward. In S. B. Klein \& R. R. Mowrer (Eds.), Contemporary learning theories: Pavlovian conditioning and the status of traditional learning theory (pp. 191-223). Hillsdale, NJ: Erlbaum.

Weinberger, N. M. (1995). Retuning the brain by fear conditioning. In M. Gazzaniga (Ed.), The cognitive neurosciences (pp. 1071-1089). Cambridge, MA: MIT Press.

Weinberger, N. M. (1998). Physiological memory in primary auditory cortex: Characteristics and mechanisms. Neurobiology of Learning and Memory, 70, 226-251.

Williams, D. R., \& Williams, H. (1969). Auto-maintenance in the pigeon: Sustained pecking despite contingent nonreinforcement. Journal of the Experimental Analysis of Behavior, 12, 511-520.

Zilles, K., \& Wree, A. (1995). Cortex: Areal and laminar structure. In G. Paxinos (Ed.), The rat nervous system (2nd ed., pp. 649-685). London: Academic Press.

Received November 9, 2001

Revision received February 11, 2002 Accepted February 13, 2002 